\title{
The influence of organic polymer on properties of mineral concentrates
}

\author{
Part II
}

Marzenna Popek, Ph.D.

Gdynia Maritime University, Poland

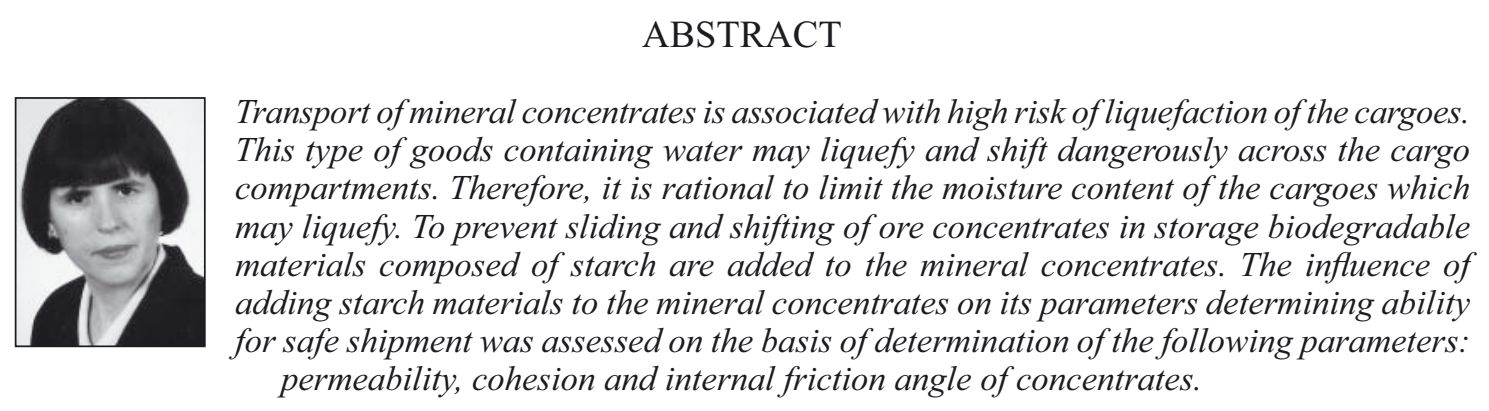

Keywords: mineral concentrates; liquefaction; shifting; starch materials

\section{INTRODUCTION}

Bulk cargo shipping has been used for many years to reduce the cost of sea transport and the transport of bulk cargoes is a vital component of international trade. Such trade requires a sufficient volume of cargo suitable for bulk handling and hence justifies a tailored shipping operation. The five major dry bulk cargoes are: coal, mineral concentrates, grain, bauxite and rocky phosphate, and the trade in bulk increases each year [1].

Mineral concentrates and other similar fine - grained materials are transported by sea in a wet state. The process has become increasingly associated with high risk of liquefaction of the cargoes. The International Maritime Organization (IMO), recognising that some losses had occurred due to improper loading, issued codes of practice for such operations $[2,3,4]$.

To each of mineral concentrates liable to liquefaction is assigned a Transportable Moisture Limit (TML) representing the maximum moisture content of such cargo to be considered safe for carriage in ships. The cargoes prone to liquefaction should never be carried without checking their moisture content. The International Maritime Solid Bulk Cargo Code (IMSBC Code) lays down that a certificate stating the relevant characteristics of the material to be loaded, including also its TML value, should be provided at the loading port. The Code provides information how the moisture content of mineral concentrates can be tested and assessed.

The liquefaction is caused by migration of moisture. The moisture migration occurs when vibration at sea progressively makes the water contained in a cargo to migrate down to the bottom of a hold. The process might eventually lead to forming a free surface triggering dangerous violent shifting the cargo from side to side. The resulting much wetter bottom layer may therefore be prone to liquefaction and provoke instability of the entire cargo even though the average moisture content of the whole cargo remains lower than the TML $[5,6]$.

In general, finer material will liquefy (due to rise of water pressure in pores) more easily than coarser grained cargo because the water moves more easily through the larger pores between coarser particles. As a result, the pore pressure in coarse material dissipates more rapidly or does not build up at all. This is a generalization because many cargoes are not all fine or all coarse but usually consist of a mixture of particles of various size. They have a wide distribution of size of particles.

Natural and synthetic polymers (and their respective composites) are currently extensively used as biomaterials and in biodegradable applications because they are available in a wide variety of composition and their properties can be tailored to meet specific demands. Differences in the manufacturing process and in the composition of the raw material can significantly alter the functionality of the final product $[7,8]$.

In recent decades a major position has been taken by the materials made of synthetic polymers processed from crude oil. The cost of their production is low while their functional properties are very good and so is their resistance to environmental influences. Their durability regarded as a favourable feature, has become a serious ecological problem 
[9]. As a result, attempts have been made to solve the problems by introducing biodegradability into polymers through slight modifications of their structure.

In the last few years it has been noticed an increasing interest in biodegradable polymers derived from annually renewable feedstock such as starch and starch-based materials [10, 11, 12]. Starch is a polymer which occurs widely in plants. In all plants starch is produced in the form of granules. In general, the linear polymer, amylose, makes up about $20 \%$ of the granule, and the branched polymer, amylopectin, the remainder. The starch molecule has two important functional group, the $-\mathrm{OH}$ group that is susceptible to substitution reaction and the $\mathrm{C}-\mathrm{O}$ $\mathrm{C}$ bond that is susceptible to chain breakage. The hydroxyl group of glucose has a nucleophilic character. By the reaction of its $-\mathrm{OH}$ group, modification of various properties can be obtained. Cross-linking or bridging the $-\mathrm{OH}$ groups changes the structure into a network thus increasing the viscosity and reducing water retention.

Chemical and physical properties of starch have been widely investigated because it is easy to convert it into a thermoplastic and then to use it in different applications. A favorable feature of such material is its ability to absorb large quantities of water from the material of high humidity.

In this work the results of the investigation on possible using the starch as an absorber (hydrophilic material), are presented.

\section{EXPERIMENTAL PROCEDURE}

\section{Material}

For the tests in question was used a sedimentary lead concentrate (sedimentary galena) composed mainly of $\mathrm{PbS}$.

The main component of the concentrate is the mineral galena whose chemical formula is $\mathrm{PbS}$ (lead sulphide). The sedimentary galena is a product of gravimetric separation of large mineral particles. The lead content in the sedimentary galena amounts to about $80 \%$. The water content in the sedimentary concentrate is equal to $1 \div 2 \%$. The sedimentary galena is empirically judged as a material "which may liquefy if shipped above the TML".

The following starch materials were tested (potato starch obtained from Potato Industry Company, Luboń, Poland):

- cross-linked starch - diamylaceus phosphate - "Lubostat"

- cross-linked starch - acetylic diamylaceus adipate - "AD"

- natural starch - a granulated product

The samples of starch materials were in a granular form. The experiments were conducted for samples of a concentrate without starch materials and of mixtures containing 99.5\%,99\% and $98 \%$ of the concentrate and $0.5 \%, 1 \%$, and $2 \%$ of starch materials, respectively. The used starch materials are classified as a product of a low environmental impact.

\section{Methods}

The influence of adding starch materials to the mineral concentrates on their parameters which determine ability for safe shipment by sea, was assessed on the basis of determination of the following parameters:

\section{Permeability of concentrates}

The permeability is the rate at which water under pressure can diffuse through the voids in the mineral concentrates. Such materials are permeable to water because the voids between the particles are inter-connected. The degree of permeability is characterized by the permeability coefficient $\mathrm{k}$, also referred to as hydraulic conductivity.

According to the classification of soils, based on their permeability coefficient, mineral concentrates are the materials with a low degree of permeability. The permeability of mineral concentrates depends primarily on the size and shape of grains, shape and arrangement of voids, void ratio, degree of saturation, and temperature.

Permeability is an important parameter which determines the ability to liquefy the solid bulk cargoes in conditions of maritime transport. Liquefaction occurs first at the bottom layer of cargo as a result of filtration of water from the upper layers of cargo and for this reason its permeability should be determined.

\section{Measurement of cohesion and internal friction angle}

The estimation of cohesion and internal friction angle was performed in a direct shear apparatus by carrying the shearing with the use of the lower and upper part of displacing box containing the tested concentrate. In the experiment the samples were compacted in a dry state. The moisture content corresponded to the TML value estimated by means of Proctor C/Fagerberg Test.

The cohesion does not occur in dry materials with pores entirely filled with air nor in moist materials having pores entirely filled with water. The cohesion increases with the increasing content of water and reaches its maximum values at a moisture approaching the TML, and then it goes down again. The internal friction angle reaches its minimum value when the moisture content is choses close to TML [13].

The $0.5 \%$ and $2 \%$ content of starch material in mixture with sedimentary galena does not significantly changes grain size distribution. Starch absorbed water from the mixtures at the amount approximately proportional to the starch material content in the mineral concentrate. It can be noticed that modified starch shows a higher solubility than natural starch. In general, higher TML values were observed in the case of testing the sedimentary galena mixed with $2 \%$ of starch material [14].

In the experiments for estimation of the permeability, cohesion and internal friction angle, the samples were compacted. The consolidation conditions in the holds were simulated by applying the vertical loads equal to: $0 \mathrm{~N}, 98 \mathrm{~N}$, $196 \mathrm{~N}, 294 \mathrm{~N}$ and $490 \mathrm{~N}$, corresponding to the normal stresses of: $0,1.532 \cdot 10^{4} \mathrm{~N} / \mathrm{m}^{2}, 3.0645 \cdot 10^{4} \mathrm{~N} / \mathrm{m}^{2}, 4.589 \cdot 10^{4} \mathrm{~N} / \mathrm{m}^{2}$, $7.659 \cdot 10^{4} \mathrm{~N} / \mathrm{m}^{2}$, respectively. The test of samples without stresses corresponded to the stress conditions of cargo in the hold during its loading. The increasing values of normal stresses represented the changes in the bulk cargoes during their shipping by sea.

\section{RESULTS AND DISCUSSION}

The results of the permeability tests are presented in Tab. 1.

Based on the results of the tests, the effect of different content of the samples on their permeability was observed.

The maximum value of the permeability coefficient $\mathrm{k}$ was achieved for the mineral concentrate without any starch materials; it reached the value of $1.46 \cdot 10^{-2} \mathrm{~m} / \mathrm{s}$. The value indicates that the tested concentrate may be classified as prone to liquefaction because its permeability coefficient significantly exceeds the limiting value $\mathrm{k}=10^{-8} \mathrm{~m} / \mathrm{s}$ [15].

Large spaces between particles, confirmed by the porosity ratio, mean that the sedimentary galena is the cargo of the highest permeability among the tested samples. 


\begin{tabular}{|c|c|c|}
\hline \multirow{2}{*}{ Sample type } & \multicolumn{2}{|c|}{ Permeability coefficient $[\mathbf{m} / \mathbf{s}]$} \\
\cline { 2 - 3 } & $\begin{array}{c}\text { Sedimentary lead concentrate }+\mathbf{1 \%} \text { of starch material } \\
\text { Sedimentary lead concentrate }+\mathbf{2 \%} \text { of starch material }\end{array}$ \\
\hline Sedimentary lead concentrate & $1.46 \cdot 10^{-2}$ & $5.82 \cdot 10^{-4}$ \\
\hline Sedimentary lead concentrate + Lubostat & $1.8 \cdot 10^{-3}$ & $1.12 \cdot 10^{-3}$ \\
\hline Sedimentary lead concentrate + AD & $2.34 \cdot 10^{-3}$ & $2.34 \cdot 10^{-3}$ \\
\hline Sedimentary lead concentrate + granulated starch & $3.84 \cdot 10^{-3}$ & \\
\hline
\end{tabular}

The presence of starch materials in the concentrate material reduces, by absorption of water, their ability to filtration. The ability to absorption of water is related primarily to the composition of starch material and the percentage of starch in a mixture.

For all samples with starch material the decrease of permeability was found. If the content of starch material in the mineral concentrate increases the value of permeability coefficient decreases. The greatest decrease of the permeability coefficient was observed in the mixture containing $2 \%$ of Lubostat.

\section{Measurement of cohesion and internal friction angle}

The changes of cohesion in function of moisture content are presented in Fig. 1 through 3.

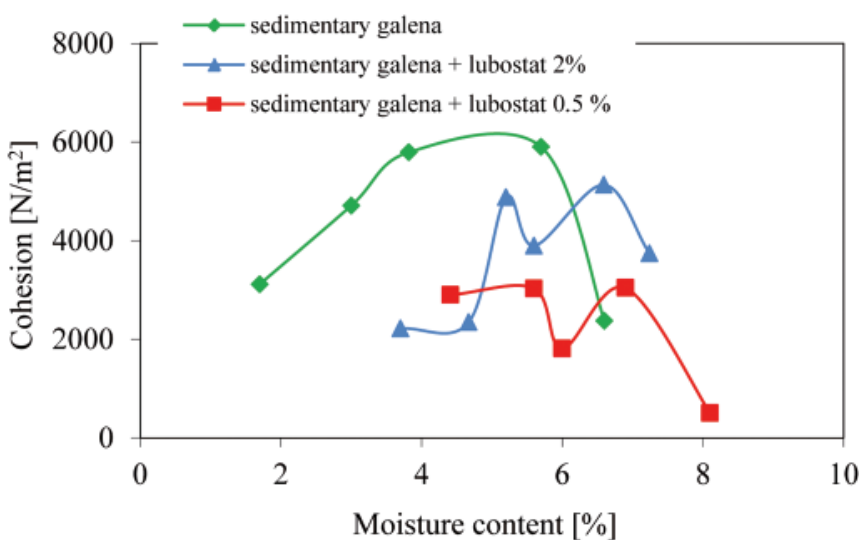

Fig. 1. The changes of cohesion in function of moisture content for sedimentary galena + Lubostat

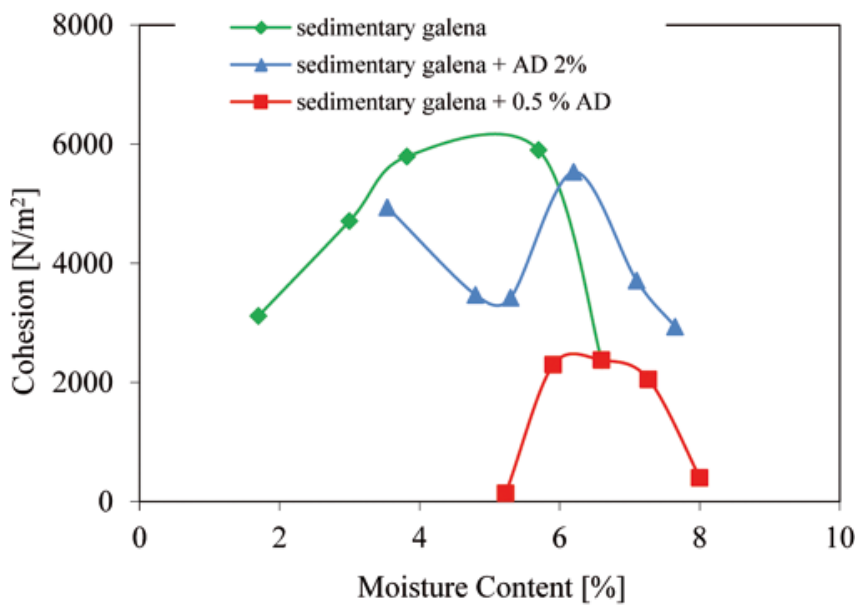

Fig. 2. The changes of cohesion in function of moisture content for sedimentary galena $+A D$

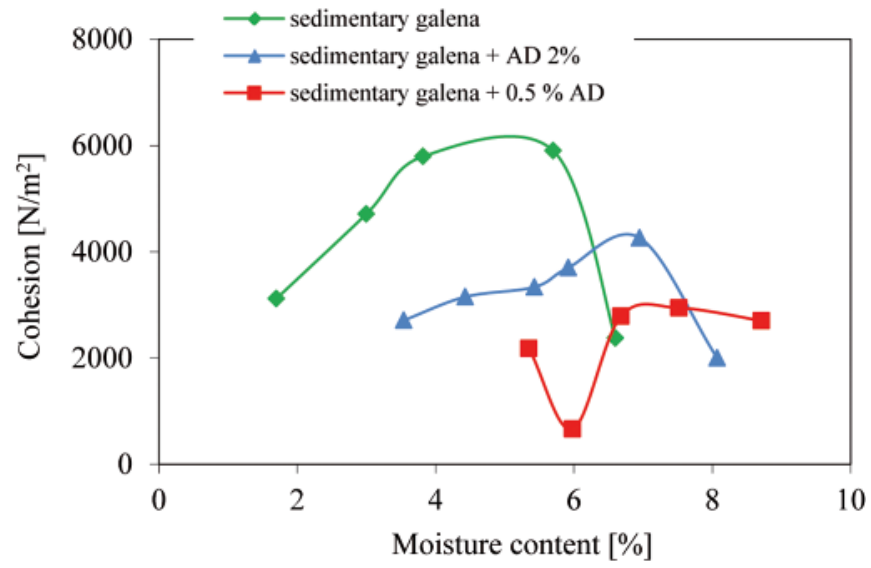

Fig. 3. The changes of cohesion in function of moisture content for sedimentary galena + granulated starch

The result indicates that the starch materials significantly change the cohesion. The presence of the starch materials in mineral concentrates tends to reduce cohesion. In all tested samples cohesion increases with the increasing of moisture content and reaches its maximum with the moisture approaching the TML, and then it goes down. The extreme values are not reached at the same moisture content for all mixtures. The maximum values of cohesion are affected by the type of mixture. The result confirms presence of correlations between TML values of mixtures and maximum values of cohesion. For mixtures containing $0.5 \%$ of starch material, the greatest decreasing of maximum cohesion was observed.

The changes of internal friction angle in function of moisture content are presented in Fig. 4 through 6 .

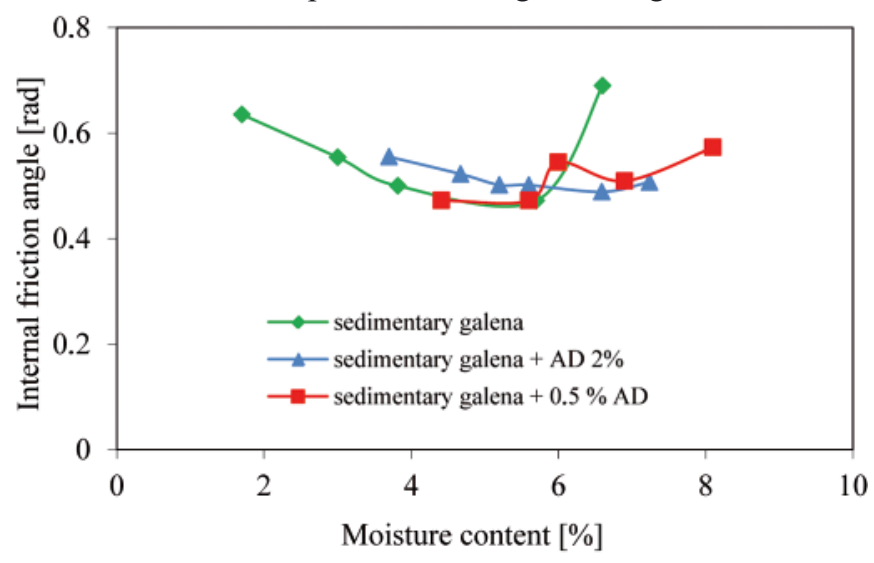

Fig.4. The internal friction angle in function of moisture content for sedimentary galena + Lubostat

For the sedimentary galena with starch material no significant changes in values of internal friction angle are observed. The presence of starch materials in the tested mineral 


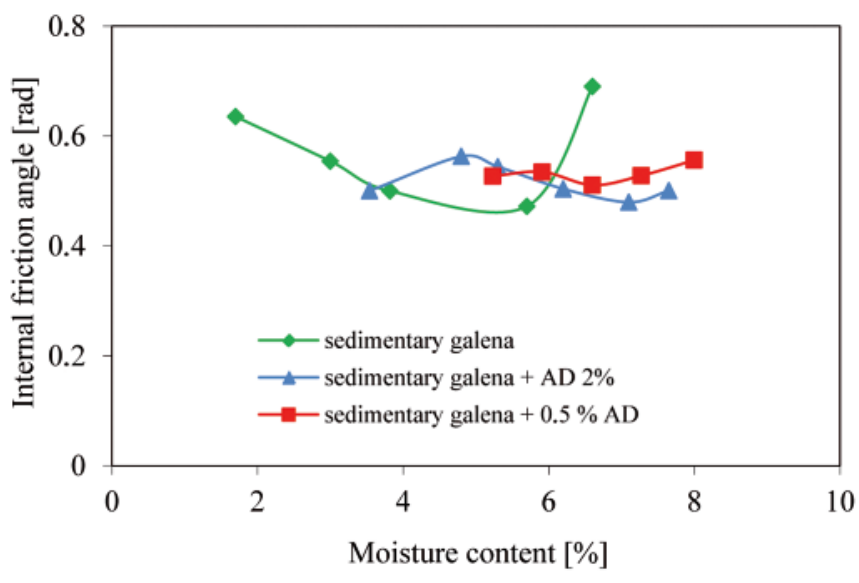

Fig. 5. The internal friction angle in function of moisture content for sedimentary galena $+A D$

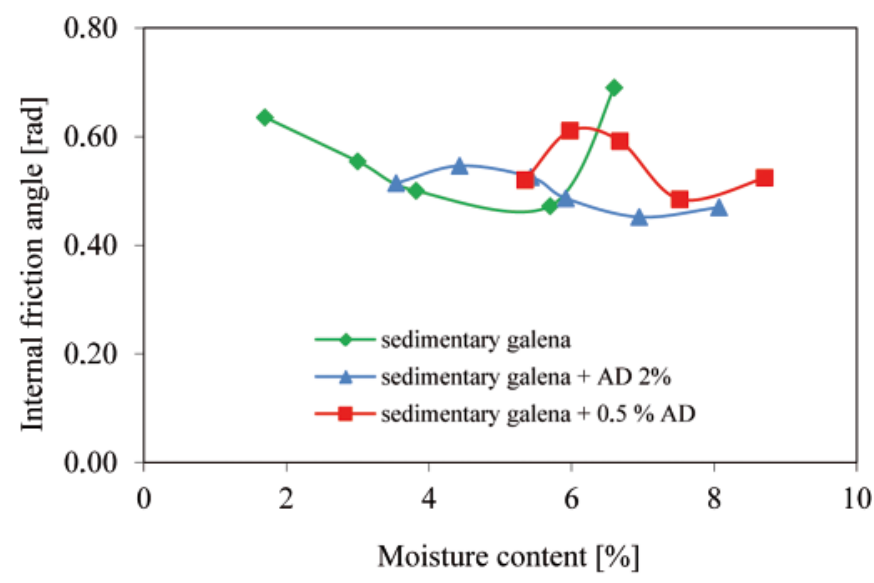

Fig. 6. The internal friction angle in function of moisture content for sedimentary galena + granulated starch

concentrate influences the minimum value of internal friction angle. In each case the values are higher than those for the sample without starch material. For mixtures containing $0.5 \%$ of starch material the greatest increase of minimum internal friction angle was observed. The minimum values are not reached at the same moisture content for all samples. Content of starch material in mixture contributes to increase of the moisture content at which the maximum value of internal friction angle is achieved. Increasing the internal friction angle reduces the proneness of mineral concentrate to shifting.

\section{CONCLUSION}

For all samples with starch material, a reduction of the degree of permeability was obtained. Starch materials absorbed water from the mixtures at the amount approximately proportional to the starch material content in mineral concentrates. The results of the tests indicate that the permeability influences significantly the properties of the concentrates, important from the point of view of sea transport safety.

Water absorption and swelling the particles results in a reduction of space between the particles and, as the migration of water is thus more difficult, the concentrate capability to filtrate water into the lower part of cargo where the liquefaction process usually starts, is also reduced.
In consequence, starch materials prevent mineral concentrates against drainage of water from pores between particles, and consequently, sliding and shifting such cargoes in storage.

The comparison of the cohesion, internal friction angle and TML values confirms that for the tested mixtures the correlation occurs between values of the quantities in question. Due to the presence of starch materials in the mixtures the risk of passing mineral concentrates into the liquid state is lower.

\section{BIBLIOGRAPHY}

1. Roberts S., Marlow P.: Casualties in dry bulk shipping.Maritime Policy, pp. $437 \div 450,2004$

2. International Maritime Organization: International Convention for the Safe of Life at Sea-SOLAS 1974/1978.London, 2001

3. International Maritime Organization: Code of practice for the safe loading and unloading of bulk carriers, BLU Code. London, 2004

4. International Maritime Organization: International Maritime Solid Bulk Cargoes Code-IMSBC Code. London, 2009

5. Sieder R., van den Beukel A.: The liquefaction cycle and the

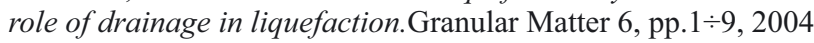

6. Eckersley J.D.: Coal cargo stability.TheAusIMM Proceedings, No. 1 , pp. $33 \div 42,1997$

7. Demirgoz D. et al.:Chemical modification of starch based biodegradable polymeric blends: effects on water uptake, degradation behaviour and mechanical properties. Polymer Degradation and Stability 70, pp. $161 \div 170,2000$

8. Ramaswamy M. \& Bhattachary M.: Properties of Injection Moulded Blends of Starch and Modified Biodegradable

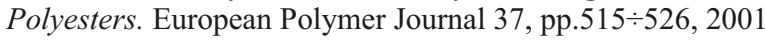

9. Figiel A., Zięba T., Leszczyński W.: The effect of moisture content and composition on tensile properties of the synthetic polymer/starch composition, Polimery 49, pp. 547 $\div 550,2004$

10.Bastoli C., Belloti V., Baerel L.: Eur. Pat. Appl. WO 90/EP 1286, 1990

11. Bulativic, S. M.: Use of organic polymers in the flotation of polymetallic ores: A Review, Minerals Engineering 12/4, pp. $341 \div 354,1999$

12.Tudoracchi N., Lipsa R.: Comparative study on starch modification with lactic acid and polylactic acid, Polimery 51, pp. $425 \div 430,2006$

13. Popek M.: The evaluation of Ability to Liquefaction of Solid Bulk Cargoes, The 3-rd Safety and Reliability International Conference, Warszawa, 2003

14.Popek M.: Liquefaction of Water Saturated Mineral Concentrates in Mixtures with starch, Zeszyty Naukowe UE, No. 211, Poznań, pp. 102 $\div 112,2011$

15.Head K.: Soil Technicians'Handbook. Pentech Press Publishers, London, 1989.

\section{CONTACT WITH THE AUTHOR}

Marzenna Popek, Ph. D.

Department of Chemistry and Industrial Commodity Science,

Gdynia Maritime University Morska 83

81-225 Gdynia, POLAND e-mail: marzenap@am.gdynia.pl 